\title{
The effect of slope curvature in rock mass shear strength derivations for stability modelling of foliated rock masses
}

\author{
S. Narendranathan Coffey Mining Pty Ltd, Australia \\ R.D.H. Thomas Coffey Mining Pty Ltd, Australia
}

J.M. Neilsen Coffey Mining Pty Ltd, Australia

\begin{abstract}
In open pits the instability mechanisms are multifaceted involving; shearing along or over the asperities of the defect surface and/or block rotation at very low normal stresses. At higher degrees of confinement, shearing along or through asperities and block rotation including rock mass failure due to intact rock breakage can occur. It is common to have pit designs with varying profiles resulting in concave, straight and convex geometries. This difference in wall geometry would result in varying magnitudes of effective shear strength being mobilised. The contribution of the lateral confinement to the degree of shear strength mobilised is often overlooked in design. In this paper a case study will be presented, which compares the different slope performance outcomes within similar geotechnical conditions with the only variant being the slope geometry and the influence of lateral confinement. An algorithm is developed, based on observations from this site case study, linking the concavity of a slope face to the degree of (extra) shear strength mobilised. It is the authors intent that this algorithm can be used in a similar manner to which highway engineers use 'curve-speed models' to determine safe approach speeds for corners given a particular road curvature, (in our case pit slope concavity) and approach speed (rock mass characteristics). This relationship has been implemented for forward analyses at the mine in question; however the authors acknowledge that further work needs to be undertaken so as to ensure the validity of the relationship for generalised application.
\end{abstract}

\section{Introduction}

There are a number of constitutive models currently being applied by rock mechanics practitioners for the purpose of deriving rock mass shear strength parameters, for example the Mohr-Coulomb and Hoek-Brown models. These models are generally quite effective when applied appropriately. One of the key aspects that govern the successful application of any such models is the confinement at which the respective strength parameters are calculated.

In most pit slope stability scenarios, a shear type failure criterion is conventionally assumed to govern sliding failure, and it is assumes that the total strength mobilised by a rock mass hinges upon the confinement effected, i.e. the normal stress. In a pure rock mass (circular or rotational) failure the confinement is related to the depth of failure and the density of the material. However, in foliated rock masses the instability mechanism requiring assessment, is usually a stepped path or a kinematic (planar or wedge sliding) mechanism. Hence the confinement effected is better linked to the geometry of the unstable blocks relative to the slope face.

It is common to have pit slope faces excavated with varying degrees of concavity, i.e. pit re-entrants, etc. Variances to plan geometry will affect how circumferential stresses are distributed about the pit walls and toes; this will in turn influence the geometry and volume of resulting wedge and/or planar failures. These aspects have been investigated by a number of authors to date, Förster (1966), Lutton (1970), Stacey (1973), Hoek and Bray (1981) and Armstrong and Stacey (2003). 
The key principle identified in these papers, is the concept of minimum curvature to maintain slope stability. This paper takes this concept a step further, and quantifies the specific levels of 'strength gain' as a result of increased lateral confinement and how this can be used to optimise slope geometry.

It is acknowledged by the authors that there are a number of three-dimensional (3D) modelling packages available within industry that would adequately account for this aspect. However most site based engineers are limited by time and usually apply two-dimensional (2D) methods to assess/reassess designs 'on the fly'.

Through the presentation of a case study of an operating mine in Western Australia the authors intend to develop a site specific corollary between effected confinement and slope curvature. It is the intent of the authors that this relationship would be used by the site practitioners for future design assessments.

\section{$2 \quad$ Literature review}

A number of authors have investigated the effects of plan geometry on stress distributions around pit walls and the resulting effect on slope stability. Summarised below are the most relevant papers that the authors have drawn from to formulate the basis for the case study presented in Section 4.

\subsection{Lutton (1970)}

Lutton's paper focused predominantly on observations made on engineered and natural slopes in the Kimberly region of South Africa. The pertinent points were:

- The radius of curvature of a slope crest and toe can significantly influence slope stability.

- A stable slope angle is not solely function of its height, rock mass strength, and orientation of structural discontinuities as would be modelled in 2D.

- It is also is dependent upon its plan geometry and shape of excavation.

- To undertake an adequate analysis of any slope it must be 3D, the third dimension being that of overall plan configuration.

\subsection{Stacey (1973)}

This paper focused on the distribution of stresses around pit slopes of varying radii of curvature which was verified using 3D finite element techniques. He concluded that:

- Circumferential stresses depended not only on the plan radius of curvature, but also the configuration of the pit.

- Pits with an 'intermediate' radius of curvature had circumferential stresses equal to the circular pit.

- Zones of lower and higher radii of curvature had higher and lower circumferential stresses respectively.

\subsection{Hoek and Bray (1981)}

Hoek and Bray put forward some guidelines based on their experience and observations that relate the radius of curvature of a slope to its height as follows:

- Where a concave slope has a radius of curvature less than its height, the slope angle can be steepened by $10^{\circ}$.

- A convex slope with a radius of curvature less than its height should be flattened by up to $10^{\circ}$.

- As the radius of curvature increases, the correction should be decreased until the radius of curvature is twice the slope height when the correction will be zero. 


\subsection{Armstrong and Stacey (2003)}

This paper focused predominantly on investigating the maximum volume of wedges that might fail given a particular plan slope geometry. The main points here were:

- The plan radius of curvature has a parabolic influence on the maximum possible wedge that could geometrically form.

- Slopes with large concave plan radii of curvature have very shallow dipping wedges that would not fail under ordinary conditions. To increase the dip of the line of intersection the failure would have to be reduced from the largest possible wedge to one that is somewhat smaller.

- The paper concluded that there was no definitive design data available for engineers to use in the design of rock slopes with plan geometries with radii other than planar.

\section{Definition of problem}

On operational mine sites it is common practice for site based engineers to employ 2D limit equilibrium modelling packages to undertake minor to mid-level design changes. Something that cannot effectively be taken into account is the degree of lateral confinement mobilised within a slope sector due to its shape or plan concavity. On the flip side, convex profiles or 'bullnoses' are notorious for initiating planar/wedge type sliding instabilities, due to the lack of lateral confinement at the edges of bullnoses.

It can be a somewhat challenging process to account for the loss or apparent gain in confinement as a result of varying slope profiles in a 2D modelling package. However, should this relationship be developed for a given site (along the lines of what Lutton (1970) and Hoek and Bray (1981) did), it could prove to be a powerful tool as it would offer the site based engineer with a method of adjusting interpreted shear strength parameters for use in forward assessments.

An example of the intended application of such a relationship would be as follows:

1. Let us take an operating mine site, where the in situ rock mass conditions have been extensively studied. Rock mass parameters have been quantitatively assessed with a reasonable degree of confidence.

2. Say now within this site a concave section of slope has been identified by management for optimisation due to its general robust performance. Let us also assume that in areas where the concavity of the slope is reduced, i.e. tending to be somewhat straighter or more convex than concave, instabilities of varying degrees of significance are noted. NB - the geology, associated structure, groundwater regime and other relevant parameters (i.e. excavation practices) are the same, the only variant being the reduced concavity of the slope profile.

3. The undertaking of the optimisation assessment usually falls on the site based engineer, who has to provide a redesign in a relatively short space of time, without the benefit of extensive 3D modelling.

4. It is the intent of the authors to develop an easy to use site specific relationship that relates the degree of curvature of a slope to the 'gain' in lateral confinement, which can in turn be expressed as a percentage 'gain' in the strength of the overall rock matrix within that particular zone.

The case study presented below, builds on the work done by the above authors to outline the process by which a relationship was developed that correlates varying degrees of concave slope curvature to increases in lateral confinement. 


\section{$4 \quad$ Case study}

\subsection{Background}

\subsubsection{Generalised geology}

The rock mass within which this site is situated can be described as a late Archaean aged anisotropic marine sedimentary sequence. The geology is structurally complex with multiple generations of folding and faulting. The rock units that host the pit walls consist primarily of Banded Iron Formation (BIF). The pervasive rock fabric is bedding which dips moderately $\left(25\right.$ to $\left.40^{\circ}\right)$ to the southwest within the existing pit; there is considerable undulation due to small scale folding. There are a number of weak bands that are interbedded within the BIF units, which when undercut typically result in slope instabilities. Intact rock strengths are typically around $20 \mathrm{MPa}$.

The mean Rock Mass Rating $\left(\mathrm{RMR}_{89}\right)$ (Bieniawski, 1989) of the rock mass has been assessed as approximately 40, as shown in Table 1.

Table $1 \quad \mathrm{RMR}_{89}$ of the rock mass

\begin{tabular}{lcc}
\hline Parameter & Rock Mass Condition & Rating \\
\hline Strength & $20 \mathrm{MPa}$ & 4 \\
RQD (\%) & $\sim 30$ to $50 \%$ & 8 \\
Fracture spacing $(\mathrm{mm})$ & $60-200 \mathrm{~mm}$ & 8 \\
Condition of discontinuities & Smooth to rough, generally tight, & 10 \\
& minor hard infill & \\
Groundwater & Damp & 10 \\
RMR $_{89}$ & & 40 \\
\hline
\end{tabular}

\subsubsection{Weathering}

Typical depths of weathering were assessed to be approximately $80 \mathrm{~m}$ below surface, although there are areas, associated with fault zones, where observations confirm the weathering depth can be higher.

\subsubsection{Hydrogeological conditions}

The pit in question is being mined above the water table, hence apart from seasonal rain events; groundwater does not pose an issue on this site. There were certain areas within this deposit that contained (compartmentalised) perched water tables. However this particular pit was not affected.

\subsubsection{Stability concerns}

The majority of the instabilities that occur on this site are as a result of undercutting the weak bands associated with the variably dipping bedding. Where these bands are undercut planar sliding type instabilities occur, initially on the batter scale, but tend to propagate up dip and can affect multiple benches.

These bands had been extensively studied by others and generally the following is understood and accepted:

- Thickness - varies between 300 and $600 \mathrm{~mm}$.

- Base friction angle $(\Phi b)-18^{\circ}$, determined by a substantial campaign of tilt testing and verified by laboratory direct shear test work. NB clay filled joints were excluded from this comparison with direct shear tests. 
- Large scale roughness - almost negligible (refer to Figure 1, an example of such an instability).

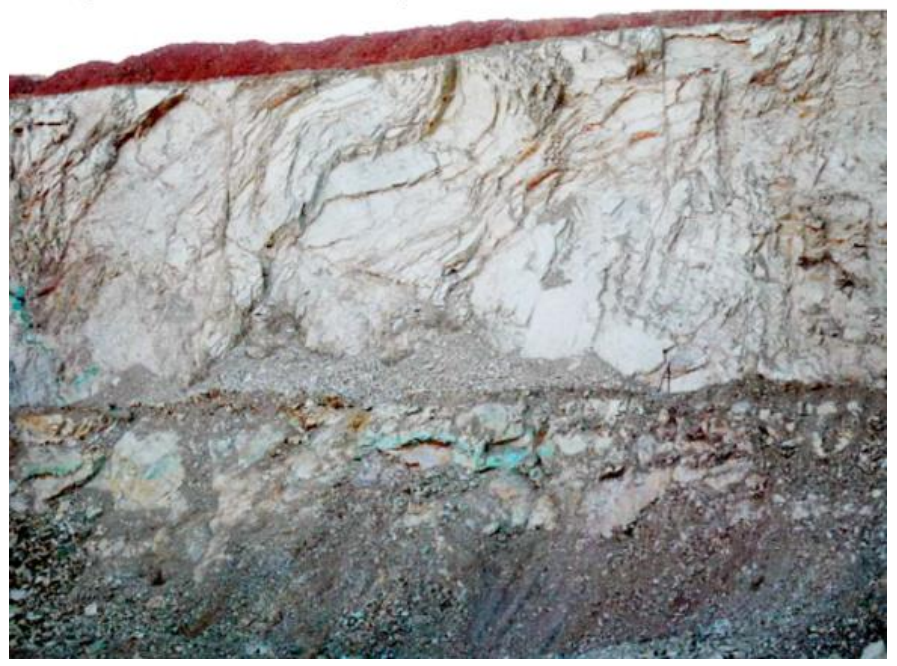

Figure 1 Example of typical instability

\subsection{Site observations}

The authors, over the last few years have been involved with the design and subsequent performance assessment of most of the slopes within this particular site, and in this capacity have made a number of pertinent observations with respect to the failure geometry. These observations form the framework for the relationship that is later developed, which attributes the degree of slope curvature to increases in mobilised shear strength, as presented in Section 4.4.

The relevant observations are as follows:

- The conclusion noted, with the benefit of having undertaken a number of forensic evaluations of instabilities on this site was that in all of the situations the cause of the instability had been attributed to these low strength 'bands'.

- In majority of the cases that instabilities were noted to initiate on slight convex profiles; and upon being back-analysed, they typically returned effective friction angle values of anywhere between 16 and $20^{\circ}$. Hence the incorporation of $18^{\circ}$ as a base friction angle did not seem unreasonable, and confirmed the results from the somewhat extensive laboratory testing database.

- Where 'cutoff' features did not play a role, it was also noted that the lateral extents of the instabilities were defined by the change in concavity of the slope, i.e. usually $20 \mathrm{~m}$ beyond the inflexion point (into the concave section).

\subsubsection{Discussion}

The observations noted here are commensurate with Stacey's (1973) conclusions regarding the distribution of stresses around pit with varying degrees of curvature. Whereby, we know that when the long axis of a concave pit slope is normal to the maximum compressive lateral stress (over burden driving force), the effects of the lateral in situ stresses were the greatest. The only way to account for this increase in lateral stress on a 2D modelling package would be accordingly adjust the shear strength parameters to 'mimic' the change in lateral confinement. The process by which this 'adjustment' can be made is developed over the subsequent sections of this paper.

\subsection{Calculating slope curvature}

A key component of the impending relationship would be the manner in which the degree of slope curvature is quantified. The authors have chosen to define the degree of curvature as used in the civil 
engineering fields of highway/railway engineering, whereby; an n-degree curve turns the forward direction by $\mathrm{n}$ degrees over some agreed upon distance.

This definition has been espoused by the authors and applied thus:

- The change in curvature angle for this case study will be measured over a $100 \mathrm{~m}$ 'chord'. A chord being the secant line whose endpoints both lay on the circle.

- The algorithms utilised for this case study are presented in Equations 1 and 2 (refer to Figure 2):

$$
\begin{gathered}
c=2 R \sin \frac{\theta}{2}=R \sqrt{2-2 \cos \theta} \\
\theta=2 \arccos \frac{d}{R}
\end{gathered}
$$

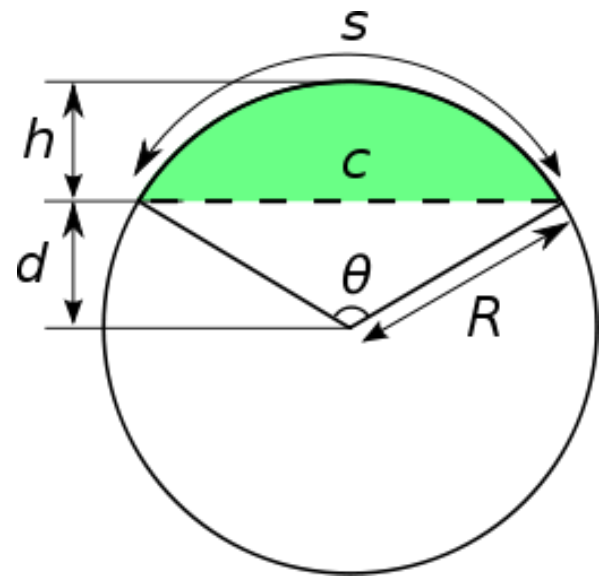

Figure 2 Illustration of the measure of curvature

\subsection{Lateral confinement and effect of mobilised shear strength}

To enable the charting and the relative comparison of the degree of slope curvature to the (apparent) confinement, across a range of slope profiles with varying degrees of stability performances the following methodology and associated assumptions have been applied:

1. Shear strength parameters will be referred to using McMahon's effective friction angle formulation (McMahon, 1971), as opposed to a combination of cohesion and friction angle calculated at a predefined confinement.

$$
\varphi^{\prime}=\tan ^{-1}\left(\frac{\mathrm{c}}{\sigma_{\mathrm{N}}}+\tan (\varphi)\right)
$$

Where:

$$
\begin{aligned}
& \Phi^{\prime}=\text { calculated pseudo friction angle } . \\
& c=\text { cohesion. } \\
& \sigma_{N}=\text { normal stress (confinement) } . \\
& \varphi=\text { friction angle. }
\end{aligned}
$$

2. The back calculation of effective shear strength (friction angles) is relatively straight forward for a slope that has failed, whereby shear strength parameters can be iteratively manipulated until a factor of safety (FS) of $<1.0$ is achieved. Any observed variations to the effective friction angle can be directly attributable to either an increase or loss of effected confinement (i.e. $\sigma_{N}$ ), using McMahon's algorithm. 
3. This is somewhat more challenging to apply towards stable slopes, as all we can definitively say is that the FS is any number greater than unity. Therefore the authors correlated the rates of slope movement, as set out by Call (1992), Zavodni (2000), Sullivan (1993) to relate to FS thus:

a. displacement rate $<1.5 \mathrm{~mm} /$ month, $\mathrm{FS}$ assumed to be $>1.5$

b. displacement rate 1.5 to $3.0 \mathrm{~mm} /$ month, FS ranges from 1.2 to $<1.5$

c. displacement rate 3.0 to $7.5 \mathrm{~mm} /$ month, FS ranges from 1.1 to $<1.2$

d. displacement rate $>7.5 \mathrm{~mm} /$ month, $\mathrm{FS}<1.1$

4. A calibration exercise was undertaken which correlated the horizontal (pit ward) displacement component as obtained from the prisms to determine the rock mass stiffness parameters, i.e. Young's Modulus etc. The assigned FS was utilised for back-analysis undertaken using a 2D finite element package; Phase $^{2}$ (Rocscience Inc., 2012).

\subsubsection{Results}

The chart plotted below is a comparison of the degree of slope curvature plotted against the back-calculated 'lateral confinement' using the process outlined above. The convention for curvature used is positive for concave slopes, and negative for convex. Slopes which have failed are shown in red squares.

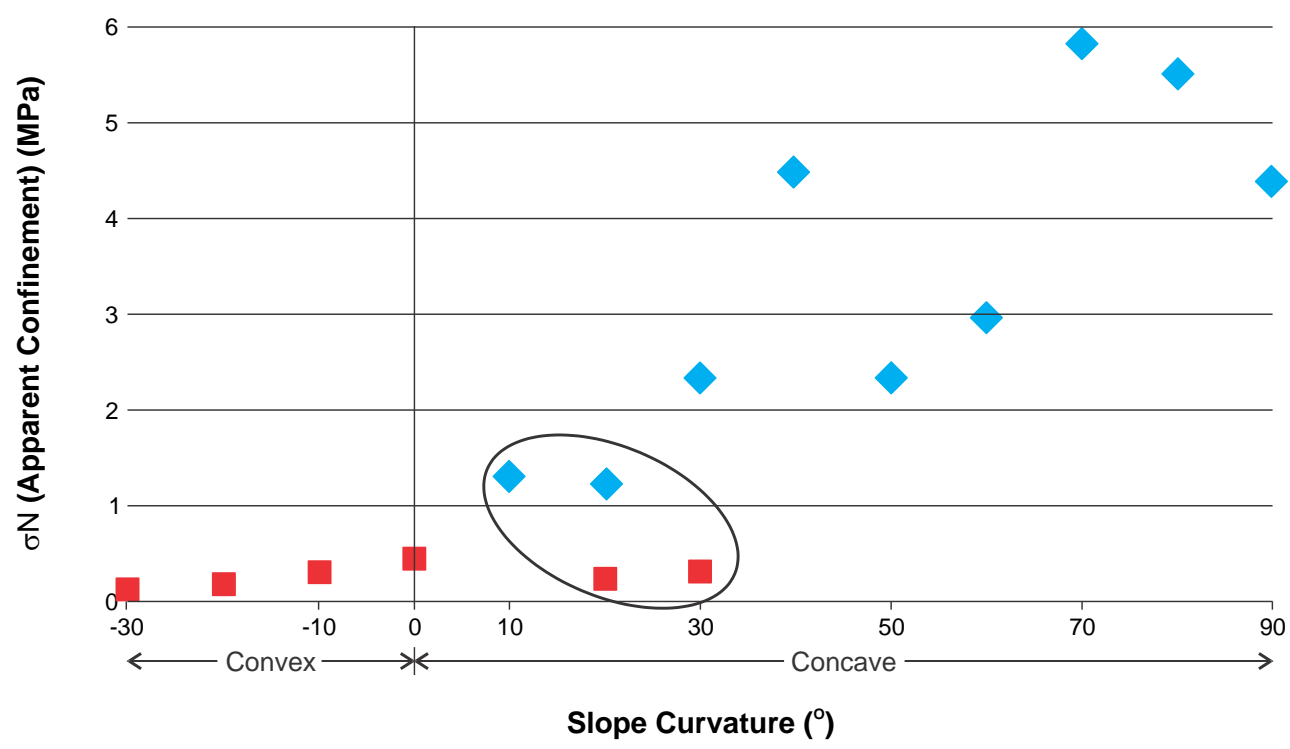

Figure 3 Apparent confinement plotted against slope curvature for a series of slopes

\subsubsection{Discussion}

The above chart depicts the reasonably significant increases in confinement noted, in some cases in excess of 4.5 MPa, which is almost nine times that at which typical (instantaneous) material parameters are quoted (generally 0.35 to $0.5 \mathrm{MPa}$ ). This can be attributed to increased slope curvature resulting in increased circumferential stresses, as noted and described by Stacey (1973).

If a line of best fit were to be applied to the chart above, it could be used to determine the effect on mobilised shear strength as a result of slope curvature. However there are a few aspects that need to be refined prior to doing so, as discussed below.

An interesting observation is noted as circled above, whereby, of the four pit slope areas which were observed, two were noted to have failed, and the other two were stable, despite exhibiting similar degrees of curvature. 
This particular observation highlights the potential limitations of this relatively simplistic corollary, particularly where unfavourably orientated 'cutoff' structures could occur, as was the case in the two noted instabilities.

There are a number of other parameters that also come into play here that will require consideration, prior to the development of a more robust relationship that could be considered for forward application. These aspects are discussed below.

\subsection{Development of a relationship}

The four pit slope areas as outlined (circled) above in Figure 3 were further scrutinised and the following relatable aspects should be noted:

- Both of the slopes which failed occurred over multiple benches (i.e. slope height greater than $20 \mathrm{~m}$ ) and were not decoupled by catchment berms. These instabilities originally initiated on a single batter ( 5 to $10 \mathrm{~m}$ in height) where the slope was noted to have a slightly increased convex profile, about $3 \mathrm{~m}$ along strike, despite being generally concave over the remaining $100 \mathrm{~m}$. NB the extents of these two instabilities were generally bounded by where the slope transitioned to a concave profile.

- For the two stable slopes it was noted that the exposures, tended to extend over $50 \mathrm{~m}$, and were decoupled every 7.5 to $10 \mathrm{~m}$ vertically, i.e. bench heights.

- Another critical aspect that was observed was the positioning of the low strength band, in the case of the unstable slopes these bands were positioned much closer close to the pit face, i.e. $3 \mathrm{~m}$. As a general observation it was established that the rock mass within a 3 to $5 \mathrm{~m}$ 'halo' surrounding this band was much 'blockier' than the remainder of the material (Figure 4).

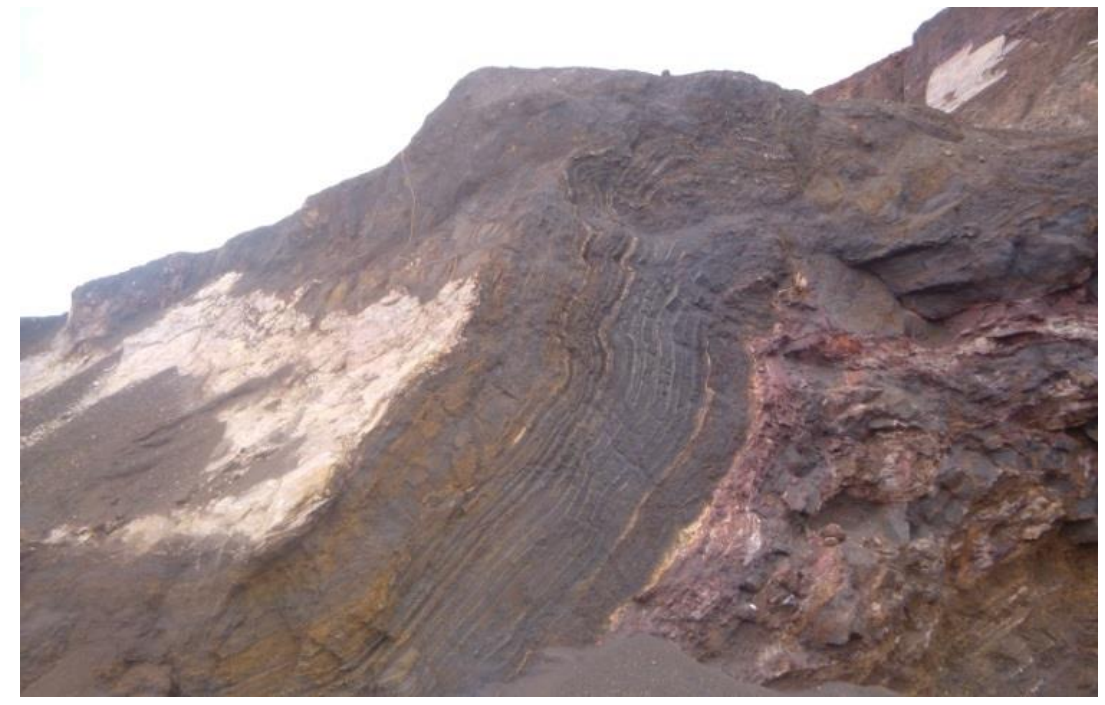

Figure 4 Photograph showing exposed failure plane

\subsubsection{Effect of circumferential stresses}

Stacey et al. (2003) have done extensive work in quantifying the effect and distribution of circumferential stresses around pit slopes with varying geometries. We know that around concave slope profiles compressive circumferential stresses will be mobilised and will act to stabilise slopes.

Stacey concludes that for a vertical to horizontal stress ratios $(K)$ of between 1 and 2, within slopes of 30 to $45^{\circ}$ (up to $500 \mathrm{~m}$ in height) the circumferential stresses can be up to $4 \mathrm{MPa}$. However as the pit slopes considered in this case study are significantly shallower, between 50 and $100 \mathrm{~m}$, the circumferential stresses are likely to be proportionally less. 
This aspect is something quite crucial, however, this study does not explicitly quantify it, in part due to the lack of in situ stress measurements, so as to be able to quantify any local stress variations in the in situ stress regime.

\subsubsection{Effect of block size on mobilised strength}

For the purposes of this assessment, it is being assumed henceforth that there are two primary contributors to the degree of mobilised shear strength, the first being the size of the blocks on the defect plane, the second being the degree of slope face curvature.

With these two aspects in mind it is now possible to further uncover the reasons behind the two instabilities noted as shown in Figure 3 (as circled). For the two instabilities in question, they occurred within the fractured 'halo' in close proximity to the slope face, in addition to which the smaller blocks ( $<0.5 \mathrm{~m}$ in thickness) would have would have contributed only modestly to the mobilisation of any shear strength along the defect plane.

With this in mind, if we are looking to develop a relationship that correlates the degree of slope curvature to mobilised lateral confinement, the observations noted within the rubbilised 'halo' could arguably be excluded as anomalous or unrepresentative.

\subsubsection{Confinement and rock mass behaviour}

In jointed rock masses (as noted within this case study), there are typically three types of deformation behaviour commonly observed, as follows:

- At low confinements - Generally intact rock breakage does not occur (unless the rock is very weak), hence the failure mechanism is one of shearing along or over the asperities of the defect surface and/or block rotation.

- At intermediate confinements - At this point there is a transition from solely shearing along/through asperities and block rotation to including rock mass failure due to intact rock breakage.

- At high confinements - At these levels of confinements, any present rock bridges are heavily confined and essentially prevent block rotation or slippage along the defect plane asperities. The only achievable mechanism would be intact shear failure through the rock.

Now if we were to reconsider the chart presented as Figure 3, excluding the instabilities that occurred within the rubbilised 'halo' the following is obtained, as presented in Figure 5 below.

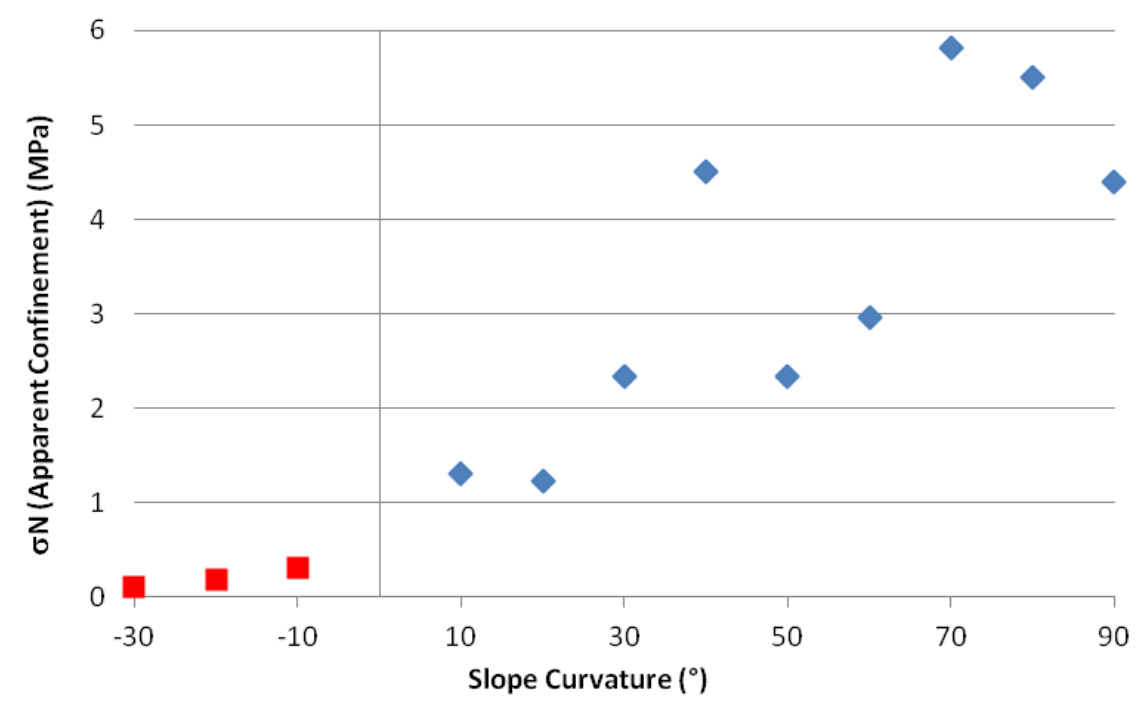

Figure 5 Apparent confinement plotted against slope curvature for a series of slopes 
The chart above shows that with $70^{\circ}$ degrees of slope curvature almost $6 \mathrm{MPa}$ of apparent lateral confinement can be mobilised. However if we were to consider the mechanics of deformation, the higher degrees of confinement essentially favours an instability mechanism that is one of intact shear as opposed to shearing along the asperities.

Bearing in mind the mechanics in motion, we can now look at the effected shear strength as a result of the mobilised confinement, and express this as a proportion of the intact compressive strength, i.e. we know that the shear strength (Equation $1, \mathrm{c}=0$ ) the mobilised shear strength would be $6 \times \tan \left(18^{\circ}\right) \approx 2 \mathrm{MPa}$, this is approximately $10 \%$ of the intact rock strength.

The replotted chart is shown below, in Figure 6.

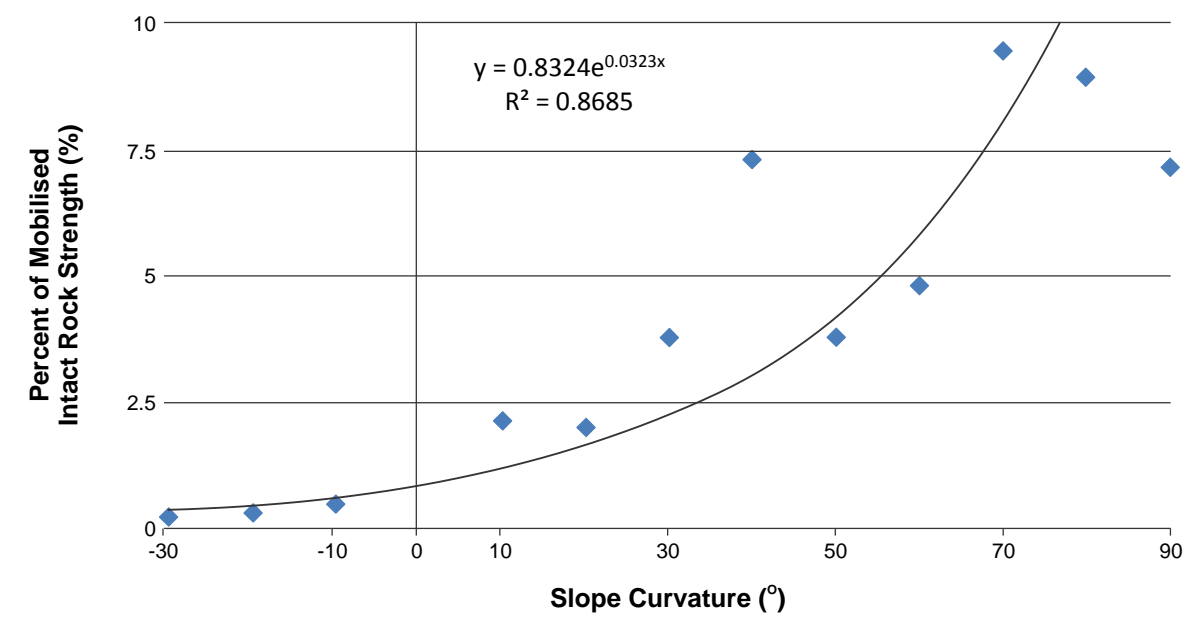

Figure 6 Apparent confinement as a percentage of intact rock strength plotted against slope curvature

With the derivation of a relationship that attributes the percentage of intact rock strength mobilised given a particular level of slope curvature, it is now possible to apply this premise to potentially optimise geometries for slopes with concave curvatures greater than say $20^{\circ}$, as the authors would instil caution in the application of this method for convex profiles.

Examination of the above chart essentially depicts a higher and a lower bound for the levels of mobilised rock strength given a particular degree of curvature. If these boundaries were to be graphically represented, the chart would be depicted as shown below in Figure 7.

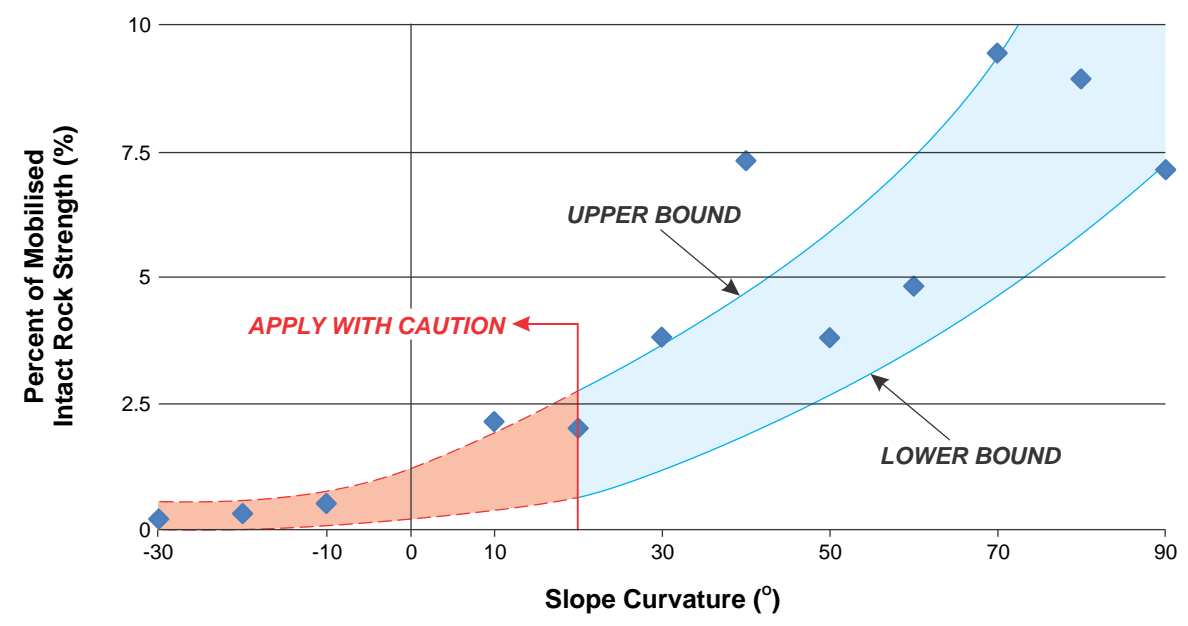

Figure 7 Apparent confinement as a percentage of intact rock strength plotted against slope curvature, highlighting the upper and lower bounds 


\subsubsection{Application of the model}

This application is primarily targeted at the site based engineer who does not have access to much more than a 2D limit equilibrium package. The authors suggest caution against its use for detailed design purposes.

The intended application process is as follows:

1. When a section of slope at the mine gets flagged for optimisation, it is invariably a concave section.

2. The 'optimisation' is generally effected in one of three ways:

a. Steeper batter face angles.

b. Double benching, i.e. increasing the bench heights from say 10 to $20 \mathrm{~m}$ without the incorporation of a decoupling berm.

c. Applying a combination of the above two features.

3. It is usually a somewhat vexing process for the site based engineer to undertake this assessment, as the engineer will have to commence this route using the original design parameters, in this case initiating the analyses with the $18^{\circ}$ effective friction angle, and develop a premise by which to upgrade this value to reflect the performance within the chosen slope sector. This cannot be appropriately accounted for using a 2D package as Stacey (1973) points out.

4. The development of these site specific charts will aid the engineer by relating the increases in concave slope curvature to increases in apparent strength, which can then be readily inputted into a 2D modelling package to assess the implication on geometry.

\subsubsection{Discussion}

The chart as derived above was subsequently employed by the mine to assess the potentially achievable (steeper) slope angles for a number of new mining areas. The performance of the steepened geometries has been plotted with respect to the upper and lower bound ranges of the chart in Figure 8 .

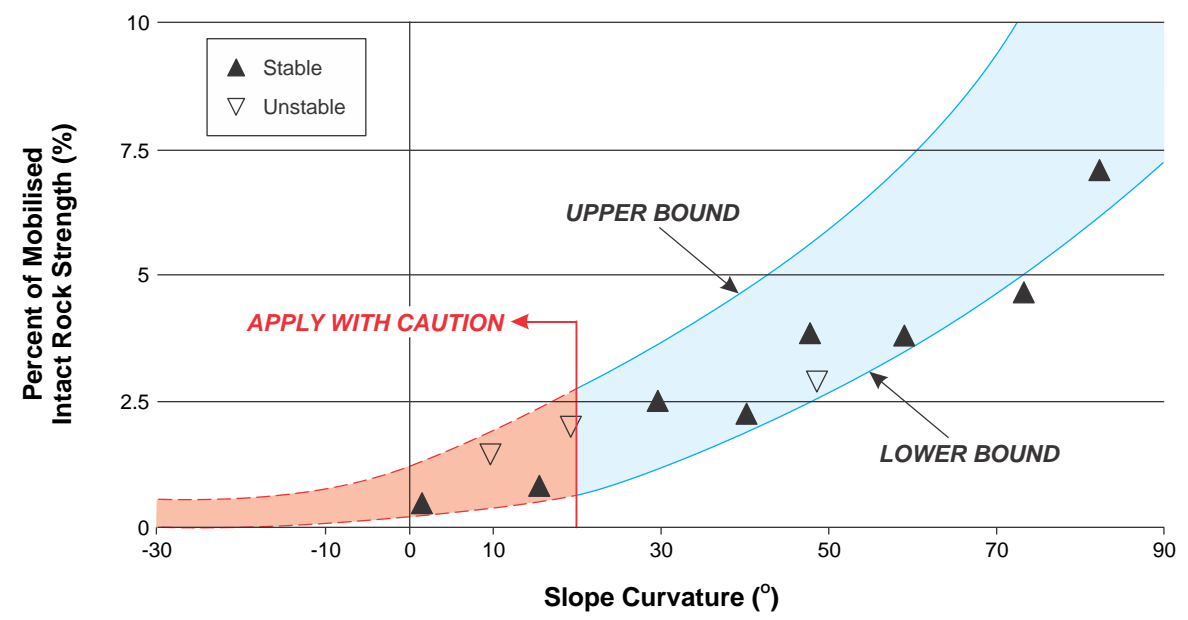

Figure 8 Performance of 'optimised' slope geometries

It can be seen that the chart is quite robust when applied in the greater than $20^{\circ}$ (slope curvature) zone. There is clearly a degree of uncertainty / unpredictability when applying this philosophy for slopes where the degree of curvature is less than $20^{\circ}$.

The explanation for this would predominantly revolve around the concept of the so called 'transitional zone', i.e. the confinement at which the behaviour of the blocks within the rock mass changes as the applied confinement increases. The confinement at which this occurs is crucial as it essentially changes the 
stress - strength relationship of the rock mass, and is a crucial indicator of the applicability of these charts. This is closely tied to the intensity of the jointing; whereby the more intensely jointed the rock mass the more susceptible the individual block are to rotation, as opposed to intact shearing.

\subsubsection{Proposed relationship}

Noting the outcomes from above, it is now possible to put forward a relationship that calculates shear strength for a given base friction angle and slope curvature, i.e. the relationship would take the form:

$$
\tau=\mathrm{F}\left(\sigma_{\mathrm{N}} \tan \left(\varphi^{\prime}\right) \text {, degree of slope curvature }\right)
$$

Now for the ease of putting forward a formula, let us assume the base case scenario $\left(\tau_{b}\right)$ for determining the shear strength of a block of rock at any given point within a slope is still defined by,

$$
\tau_{\mathrm{b}}=\sigma_{\mathrm{N}} \tan \left(\varphi^{\prime}\right)
$$

Now there is still the question of defining an appropriate relationship for the behaviour of the material below the transitional stress state, for the purposes of this case study it is assumed that the transitional stress state occurs at a confinement approximately equal to $2.5 \%$ of the intact rock strength. This value has been chosen based on the outcomes as observed in Figure 8. So going forward, data points observed below this zone will be excluded.

Henceforth the form of the relationship, at stresses greater than the transitional state would be as follows:

$$
\tau_{\mathrm{ult}}=\tau_{\mathrm{b}}+\Delta \varphi
$$

Where:

$$
\Delta \varphi=\text { a function of slope curvature. }
$$

The following chart of the back calculated ultimate shear strength against the slope curvature has been plotted as a scatter in order to observe any potential relationship.

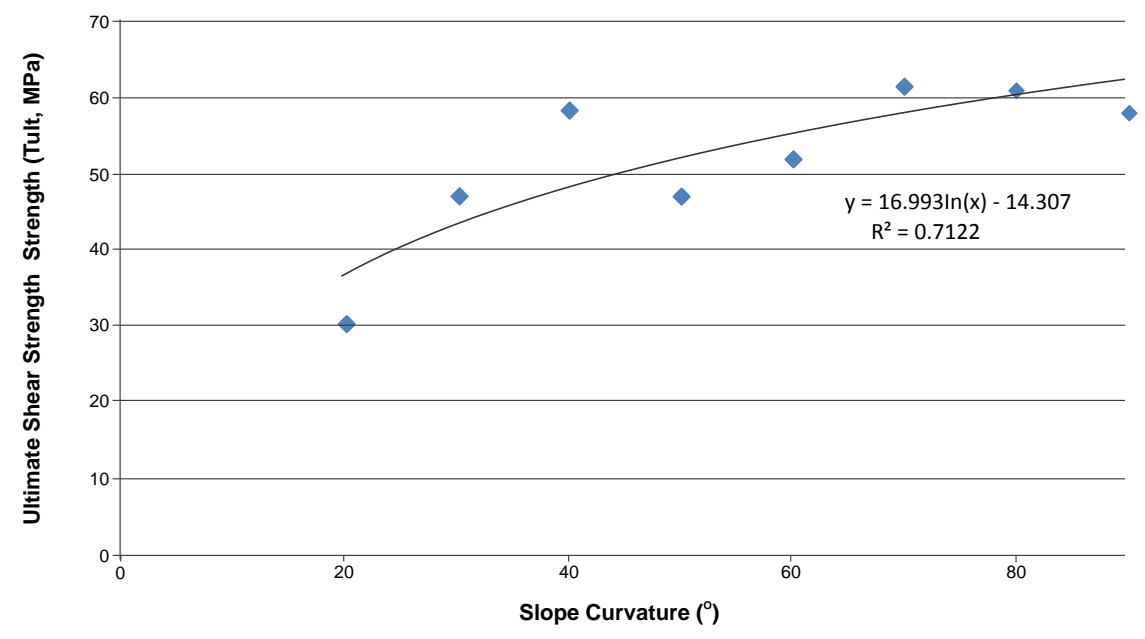

Figure 9 Back-analysed ultimate shear strength against slope curvature

Based on the observations above it can be seen that the relationship for $\Delta \varphi$ would take the following form:

$$
\Delta \varphi=\mathrm{A} \ln (\text { slope curvature })+\mathrm{B}
$$

Where:

$A$ and $B$ are site specific factors.

Therefore, with respect to this case study, the relationship would take the form:

$$
\tau_{\text {ult }}=\sigma_{\mathrm{N}} \tan \left(\varphi^{\prime}\right)+\mathrm{A} \ln (\text { slope curvature })+\mathrm{B}
$$




\section{$5 \quad$ Discussion and further work}

This case study has been successful in building on the work done by Lutton (1970), Stacey (1973), Hoek and Bray (1981) and Armstrong and Stacey (2003) to develop a series of site specific stability charts correlating the effect of plan slope curvature to achievable increases in slope angles. The authors acknowledge that further work that needs to be undertaken to validate the relationship presented as Equation 8 for ubiquitous application; the sections below discuss these aspects.

\subsection{Effect of circumferential stress}

A very important aspect which needs to be factored into the above algorithm Equation 8 is the effect of circumferential stresses. From a simplified perspective the calculated circumferential stress $(T)$ would be calculated as follows (assuming a purely circular pit):

$$
\mathrm{T}=\mathrm{F} / \mathrm{L}
$$

Where:

$\mathrm{F} \quad=$ the force exerted circumferentially over a particular area, now in a pit slope this would be a function of the overburden stress.

$\mathrm{L} \quad=$ the height of the slope.

It is most probable that the A factor in Equation 8 will be closely related to the circumferential stresses, and will vary from site to site, the key variables being the in situ stress ratios, (which will have to be calculated from in situ measurements) and material density.

\subsection{Geological considerations}

The issue of how Equation 8 would be affected as a result of joint intensity, and how this might be captured in the equation, should also be a consideration. Jointing is not only a function of RQD or say fracture frequency, but also the number of well-defined joint sets. This is particularly crucial at low confinements (i.e. below the transitional stress state), as the better defined joint sets are; the greater the susceptibility for individual block rotation to occur.

In addition to the consideration of RQD and fracture frequency, individual joint sets need to be represented, say by using Barton's Joint Number for Q (Jn) (Barton et al., 1974) or simply as the number of individual joint sets.

Another aspect that needs to be accounted for in the algorithm would be a more robust relationship between the transitional stress, slope curvature and the related factors. The ultimate relationship should take the form, transitional stress $=F$ (slope curvature, RQD, Jn, $\Phi b$ ).

\section{Acknowledgement}

The authors wish to acknowledge Coffey Mining for providing the resources to publish this document, and thank Professor Phil Dight of the Australian Centre for Geomechanics (ACG) for undertaking a critical review of this paper.

\section{References}

Armstrong, R. and Stacey, T.R. (2003) A review of information on the influence of plan curvature on rock slope stability and its effect on the volume of wedge failures, in Proceedings 10th International Society for Rock Mechanics Congress Technology Roadmap for Rock Mechanics, 8-12 September 2003, Johannesburg, South Africa, South African Institute of Mining and Metallurgy.

Barton, N.R., Lien, R. and Lunde, J. (1974) Engineering classification of rock masses for the design of tunnel support, Rock Mechanics and Rock Engineering, Vol. 6(4), pp. 189-236.

Bieniawski, Z.T. (1989) Engineering rock mass classifications, John Wiley \& Sons, New York, 251 p.

Call, R.D. (1992) Slope stability, Society for Mining, Metallurgy and Exploration Mining Engineering Handbook, Vol. 1, pp. 881-896. 
Förster, W. (1966) The influence of the curvature of open cuts on the stability of slopes in open-work mining, in Proceedings First Congress of the International Society for Rock Mechanics, 25 September-1 October 1966, Lisbon, Portugal, International Society for Rock Mechanics, Vol. 2, pp. 193-200.

Hoek, E. and Bray, J.W. (1981) Rock slope engineering, 3rd edition, Institute of Mining and Metallurgy, London, pp. 309-313.

Luton, R.J (1970) Rock Slope Chart from empirical Slope Data in Transactions, Society for Mining, Metallurgy and Exploration and The American Institute of Mining, Metallurgical and Petroleum Engineers, Vol. 247, No. 2, pp. 160-162.

McMahon, B.K. (1971) A statistical method for the design of rock slopes, in Proceedings of the 1st Australian - New Zealand Conference on Geomechanics, Melbourne, Australia, Vol. 1, pp. 314-321.

Rocscience Inc. (2012) Phase ${ }^{2}$ Finite Element Analysis for Excavations and Slopes software, http://www.rocscience.com/ products/3/Phase2.

Stacey, T.R. (1973) A three dimensional consideration of the stresses surrounding open-pit mine slope, International Journal of Rock Mechanics and Mining Sciences and Geomechanics Abstracts, Vol. 10, pp. 523-533.

Stacey, T.R., Yu Xianbin, Armstrong, R. and Keyter, G.J. (2003) New slope stability considerations for deep open pit mines, Journal of South African Institute for Mining and Metallurgy, Vol. 103, No. 6, pp. 373-389.

Sullivan, T.D. (1993) Understanding pit slope movements, Geotechnical instrumentation And Monitoring in Open Pit and Underground Mining, T. Szwedzicki (ed), Balkema, Rotterdam, pp. 435-445.

Zavodni, Z.M. (2000) Time-dependent movements of open-pit slopes, Slope Stability in Surface Mining, W.A. Hustrulid, M.K. McCarter and D.J.A. Van Zyl (eds), Society for Mining, Metallurgy and Exploration, Colorado, pp. 81-87. 